\title{
Infraestrutura escolar: uma análise de sua importância para o desempenho de estudantes de escolas públicas
}

\author{
School infrastructure: an analysis of its importance \\ for the performance of public school students \\ Infraestructura escolar: un análisis de su importancia \\ para el desempeño de los alumnos de las escuelas públicas
}

Raphael Rodrigues de Andrade ${ }^{1}$ Luís Henrique Romani de Campos ${ }^{2}$ Heitor Victor Veiga da Costa ${ }^{3}$

\section{Resumo}

ANDRADE, Raphael Rodrigues de; CAMPOS, Luís Henrique Romani de; COSTA, Heitor Victor Veiga da. Infraestrutura escolar: uma análise de sua importância para o desempenho de estudantes de escolas públicas. Rev. C\&Trópico, v. 45, n. 1, p. 159-190, 2021. DOI: https://doi.org/10.33148/cetropicov45n1(2021)art9

O presente artigo objetivou analisar até que ponto a infraestrutura afeta o desempenho escolar dos alunos, a partir do caso particular da rede pública de ensino, bem como, estimar o efeito das variáveis de infraestrutura e outras influências educacionais sobre esse processo de aprendizagem, através do Modelo de Regressão Linear Múltipla. Para isso, foram utilizados os bancos de dados gerados pela Fundação Joaquim Nabuco (Fundaj), examinando uma amostra do desempenho dos alunos do $6^{\circ}$ ano do ensino fundamental (antiga $5^{\text {a }}$ série) das escolas públicas da cidade do Recife, por meio da aplicação de duas provas de matemática, ao início e final do ano de 2013, e do Censo Escolar 2013, para as demais variáveis ausentes na base de dados da Fundaj. Para estimação das variáveis de Infraestrutura e outras influências educacionais, foram utilizados o Método dos Mínimos Quadrados Ordinários (MQO) e o método de seleção de variáveis de Akaike (AIC). De acordo com o modelo econométrico, os índices estudados: espaço pedagógico (bibliotecas, laboratórios, quadras e auditórios); computadores, internet e equipamentos; e serviços de utilidade pública (abastecimento de água, energia elétrica, esgotamento sanitário e coleta de lixo), mostram aumentar o desempenho escolar dos alunos, apenas

1 Mestre em Administração e Desenvolvimento Rural na Universidade Federal Rural de Pernambuco UFRPE, atuando na linha de pesquisa de Políticas Públicas, Gestão Pública e Administração Pública. https://orcid.org/0000-0001-9004-7109; rafael_rodrigues277@hotmail.com

2 PesquisadortitularNaFundaçãoJoaquim Nabuco, Graduaçãoem CiênciasEconômicaspela UEM; Mestrado em Economia pela UFPB; Doutorado em Economia pela UFPE. https://orcid.org/0000-0002-0801-7857; luis.campos@fundaj.gov.br

3 Graduação em Estatística - Universidade Federal de Pernambuco - UFPE. https://orcid.org/0000-00032525-6689; hvvdc1@de.ufpe.br 
quando associada a outras variáveis, que atendam às condições pré-estabelecidas. A principal conclusão do artigo é demonstrar que as decisões de investimento em infraestrutura não devem ser dissociadas de outras políticas educacionais.

Palavras-chave: Infraestrutura. Influência. Aprendizagem Escolar.

\section{Abstract}

ANDRADE, Raphael Rodrigues de; CAMPOS, Luís Henrique Romani de; COSTA, Heitor Victor Veiga da. School infrastructure: an analysis of its importance for the performance of public school students. Rev. C\&Trópico, v. 45, n. 1, p. 159-190, 2021. DOI: https://doi. org/10.33148/cetropicov45n1(2021)art9

This article aimed to analyze the extent to which infrastructure affects students' school performance, based on the particular case of the public school system, as well as to estimate the effect of infrastructure variables and other educational influences on this learning process, through the Multiple Linear Regression Model. For this, the databases generated by the Joaquim Nabuco Foundation (Fundaj) were used, examining a sample of the performance of students in the 6th year of elementary school (formerly 5th grade) from public schools in the city of Recife, through the application of two math tests, at the beginning and end of the year 2013, and the 2013 School Census, for the other missing variables in the Fundaj database. To estimate the Infrastructure variables and other educational influences, the Ordinary Least Squares Method (OLS) and the Akaike variable selection method (AIC) were used. According to the econometric model, the indexes studied: pedagogical space (libraries, laboratories, courts and auditoriums); computers, internet and equipment; and public utility services (water supply, electricity, sewage and garbage collection), show an increase in students' school performance, only when associated with other variables that meet pre-established conditions. The main conclusion of the article is to demonstrate that infrastructure investment decisions must not be dissociated from other educational policies.

Keywords: Infrastructure. Influence. School learning.

\section{Resumen}

ANDRADE, Raphael Rodrigues de; CAMPOS, Luís Henrique Romani de; COSTA, Heitor Victor Veiga da. Infraestructura escolar: un análisis de su importancia para el desempeño de los alumnos de las escuelas públicas. Rev. C\&Trópico, v. 45, n. 1, p. 159-190, 2021.

DOI: https://doi.org/10.33148/cetropicov45n1(2021)art9

Este artículo tuvo como objetivo analizar en qué medida la infraestructura afecta el desempeño escolar de los estudiantes, con base en el caso particular del sistema escolar público, así como estimar el efecto de las variables de infraestructura y otras influencias educativas en este proceso de aprendizaje, a través de la Múltiple 
Lineal. Modelo de regresión. Para ello, se utilizaron las bases de datos generadas por la Fundación Joaquim Nabuco (Fundaj), examinando una muestra del desempeño de estudiantes de $6^{\circ}$ año de primaria (antes $5^{\circ}$ grado) de escuelas públicas de la ciudad de Recife, mediante la aplicación de dos pruebas de matemáticas, al inicio y al final del año 2013, y el Censo Escolar de 2013, para las otras variables faltantes en la base de datos Fundaj. Para estimar las variables de infraestructura y otras influencias educativas se utilizó el método de mínimos cuadrados ordinarios (MCO) y el método de selección de variables de Akaike (AIC). Según el modelo econométrico, los índices estudiados: espacio pedagógico (bibliotecas, laboratorios, juzgados y auditorios); computadoras, internet y equipos; y los servicios públicos (agua, luz, alcantarillado y recolección de basura), muestran un aumento en el desempeño escolar de los estudiantes, solo cuando se asocian con otras variables que cumplen con las condiciones preestablecidas. La principal conclusión del artículo es demostrar que las decisiones de inversión en infraestructura no deben disociarse de otras políticas educativas.

Palabras clave: Infraestructura. Influencia. Aprendizaje Escolar.

\section{Introdução}

O debate político acerca da qualidade da educação brasileira nas últimas décadas leva à convergência do lugar comum de que a mesma é de baixa qualidade e que precisa ser priorizada pelos gestores públicos. Contudo, pouca concordância no meio político existe quanto aos caminhos a serem tomados para melhoria da qualidade da educação. No final do século XX, o principal esforço foi o de ampliar a oferta da educação básica em nível fundamental, tendo como principal meta a sua universalização. Uma vez atingidos altos níveis de atendimento da população infantil, novos desafios são postos no início do século XXI. Entre eles está a melhoria da infraestrutura e dos recursos físicos escolares objetivando melhoramento do processo de aprendizagem (AZANHA, BOBBIO, CARVALHO, 1998; 2004; 2004).

Dados do Banco Interamericano de Desenvolvimento (BID, 2011) revelam a magnitude deste desafio. Analisando os países da América Latina estimaram que cerca de $88 \%$ da infraestrutura das escolas da educação básica não dispunham de laboratórios de ciências, 73\% não tinham espaço para alimentação (refeitório), 65\% eram desprovidas de salas de informática, $40 \%$ não eram equipadas com biblioteca e 35\% não ofereciam nenhum espaço para a prática de esportes.

A pesquisa ainda revela que a situação se torna mais preocupante quando se trata da oferta de outros serviços como água potável, onde, uma em cada cinco escolas não ofertam; 10\% não dispõem de energia elétrica; um terço dos colégios não oferece número suficiente de banheiros aos alunos e as condições básicas de funcionamento para os professores e estudantes que frequentam essas escolas são insuficientes (BID, 2011). 
A situação pernambucana parece não ser muito diferente da brasileira e da América latina. O Índice de Desenvolvimento da Educação Básica (IDEB) indicou, em 2011, que cerca de 13\% das escolas possuem laboratório de ciências, $61 \%$ possuem sala de informática e apenas 52\% das escolas públicas pernambucanas dispõe de bibliotecas, demonstrando a ausência de uma estrutura física e educacional que estejam voltadas à garantia da melhoria da qualidade de ensino (QEDU, 2011).

Diante dessa realidade o presente artigo tem por objetivo, analisar até que ponto a infraestrutura escolar afeta o desempenho dos alunos, a partir do caso particular da rede pública de ensino do Recife. Para isto estima o efeito das variáveis de infraestrutura (energia elétrica, água tratada, quadras, laboratórios e outros equipamentos físico-materiais) e outras influências educacionais (estrutura familiar, renda e amizades) sobre esse processo de aprendizagem, através de análises de regressões e também observa o perfil das escolas que compõem a amostra. $\mathrm{O}$ ponto de partida foi o banco de dados gerado pela Fundação Joaquim Nabuco (Fundaj), examinando uma amostra do desempenho dos alunos do $6^{\circ}$ ano do Ensino Fundamental (antiga $5^{\text {a }}$ série) das escolas públicas da cidade do Recife, por meio da aplicação de duas provas de matemática, ao início e final do ano de 2013.

Este artigo é composto de mais 4 seções além desta introdução. Na primeira apresenta-se o referencial teórico que discute como a infraestrutura escolar é importante para o processo de aprendizagem e quais outras variáveis podem interferir nesse processo. Em seguida, apresenta-se a metodologia e a abordagem estatística utilizada. Outra seção apresenta os resultados e explora os achados apresentando como a infraestrutura se relaciona com outras variáveis educacionais. Por fim, são propostas consequências destes resultados para a condução de políticas públicas em educação básica.

\section{Infraestrutura escolar e aprendizagem}

O aluno e a sua contínua necessidade de desenvolvimento deve ser o ponto de partida para o planejamento da estruturação de uma unidade escolar. Nesse sentido, o processo de formação do espaço escolar, também compreendido neste artigo como infraestrutura, deve considerar os diversos fatores e características físicas que garantam ambientes seguros, corretamente iluminados e que facilitem o aprendizado. Afirma Vital Didonet, em publicação para o Fundescola (2002):

O espaço escolar não é apenas um 'continente', um recipiente que abriga alunos, livros, professores ou um local em que se realizam atividades de aprendizagem. Mas é também um 'conteúdo', ele mesmo é educativo. Escola é mais do que quatro paredes; é clima, espírito de trabalho, produção de aprendizagem, relações sociais de formação de pessoas. O espaço tem que gerar ideias, sentimentos, movimentos no sentido da busca do conhecimento; tem que despertar interesse em aprender; além de ser alegre aprazível e confortável, tem que ser pedagógico. Há uma 'docên- 
cia do espaço. Os alunos aprendem dele lições sobre a relação entre o corpo e a mente, o movimento e o pensamento, o silêncio e o barulho do trabalho, que constroem conhecimento (por que silêncio na biblioteca e barulho na oficina, no ateliê de artes ou mecânica?). [...] Por isso, é importante que as escolas sejam espaços funcionais, produtivos e produtores de aprendizagem.

Ao analisar o caso norte americano, Cynthia e Tschannen-Moran (2008) demonstram que a infraestrutura escolar, mais do que permitir que as atividades educacionais efetivamente ocorram, é um dos fatores que colaboram para o bom clima entre os alunos, a motivação dos professores e a participação da sociedade na vida escolar.

Analisando as contribuições de Didonet (2002), é possível destacar que o espaço escolar deve ser planejado e pensado como um local acolhedor e prazeroso para o aluno, produzindo nele uma sensação de abrigo, de forma que possibilite o surgimento de outras sensações, como segurança e satisfação, que são determinantes para o aprendizado.

Apesar de serem conceitos que estão intimamente ligados, Espaço Escolar, Infraestrutura e ambiente, Forneiro e Zabalza (apud HORN, 2004, p.35) fazem uma distinção interessante entre os mesmos. Admitem que o termo espaço escolar ou infraestrutura está relacionado ao espaço físico onde as atividades são desenvolvidas, envolvendo móveis, materiais e equipamentos, como salas de aula, instalações hidráulicas e elétricas entre outras características que deem suporte para o desenvolvimento do aluno; já o ambiente refere-se à interação que ocorre dentro desse espaço físico, envolvendo fatos e relações entre as pessoas que ali circulam.

Pensar o espaço escolar ou infraestrutura é tratar de questões físico-materiais como o acesso à energia elétrica, abastecimento de água tratada, esgotamento sanitário e manejo dos resíduos sólidos; garantir o acesso dos alunos a espaços para a prática esportiva, a bens culturais e artísticos e aos equipamentos e laboratórios de ciências em cada edifício escolar, bem como garantir a acessibilidade às pessoas com deficiência (PNE, 2015).

Por outro lado, pensar o ambiente é considerar as interações entre alunos, alunos/professores ou alunos/professores/espaços, vivenciando experiências capazes de estimular a criatividade e a imaginação, bem como desenvolver distintas formas de comunicações com outros indivíduos (BARBOSA; HORN, 2001, p. 68).

Uline (2008) destaca como as diversas características da infraestrutura podem afetar o aprendizado dos alunos, desde as questões biológicas (como iluminação, barulho e conforto térmico) a psicológica/sociais (pintura da escola e nível de manutenção da mesma), influenciando não apenas na qualidade da infraestrutura como também no ambiente escolar em que o aluno está inserido. Mais do que isto, a autora destaca que a infraestrutura também afeta a motivação do quadro de professores.

Diante do exposto, é factível que o espaço escolar ou infraestrutura seja pensado e estruturado como um local adaptável, com ambientes que propiciem e favoreçam a troca de conhecimento e saberes de cunho social e cultural, assim como de experiências cognitivas e afetivas entre os seus participantes. 
Antunes (2002) declara que a aprendizagem é o ato de reestruturar o sistema de pensamento com o qual se percebe as coisas no entorno. Para Grossi (2004), a aprendizagem é uma construção por meio da qual os conhecimentos estão em constante processo de formação, e sua aquisição se dá internamente ao indivíduo ou externamente a ele, em momentos bem definidos. Todavia, dialogar sobre a aprendizagem em si não se constitui uma tarefa fácil, em virtude das inúmeras surveys e avaliações que já foram realizadas por diversos estudiosos, possibilitando ao assunto uma larga interação com as demais áreas do conhecimento e suas dimensões.

No contexto escolar a título de exemplo, é possível identificar diversos estudos sobre os fatores que mais afetam o processo de aprendizado do aluno, e como consequência desses estudos, muitos investimentos são realizados dentro dos espaços escolares na expectativa de se obter melhores resultados educacionais. Em nível nacional, esse assunto vem sendo tratado por um conjunto de planos, leis e normas, com intuito de adequar os espaços escolares a um padrão básico de estrutura, bem como atingir uma melhoria na qualidade da educação brasileira.

O primeiro plano a ser destacado é o Plano de Desenvolvimento Educacional (PDE), que tem por objetivo "verificar se os elementos que compõem a escola estão estruturados para a oferta de educação de qualidade" (p. 19, Lei 9.394/96 (LDB) Lei de Diretrizes e Bases, Art. $4^{\circ}$, Inciso IX, que prioriza a recuperação da infraestrutura das unidades escolares, como bibliotecas e laboratórios, assegurando os padrões mínimos da qualidade e funcionamento, que influenciam de forma significativa tanto o desempenho acadêmico como o processo de aprendizagem.

O outro plano de destaque e também norteador dos quesitos básicos reativos à infraestrutura é o Plano Nacional de Educação (PNE - Meta 7.18), que tem por objetivo assegurar a todas as escolas públicas da educação básica o acesso à energia elétrica, abastecimento de água tratada, esgotamento sanitário e manejo dos resíduos sólidos, bem como garantir o acesso dos alunos a espaços para a prática esportiva, a bens culturais e artísticos e a equipamentos e laboratórios de ciências em cada edifício escolar.

A presença desse tipo de infraestrutura dentro de uma escola é tida como outra fonte de aprendizado para o aluno, funcionando como uma fonte complementar à sala de aula, possibilitando ao mesmo a aquisição de uma maior independência no processo de aprendizado, contribuindo para a aquisição de novos conhecimentos. O espaço tem que gerar ideias, sentimentos, movimentos no sentido da busca do conhecimento; tem que despertar interesse em aprender; além de ser alegre aprazível e confortável, tem que ser pedagógico (BRASIL, 2006). Quanto à organização das salas, Barbosa e Horn (2001) afirmam ser fundamental que se considere a sala como parte integrante da ação pedagógica e destacam que são fatores determinantes dessa organização o número de crianças, as faixas etárias, as características do grupo e a parceria entre professores e aluno.

Segundo Barbosa e Horn (2001), a organização adequada desses espaços, bem como dos materiais que os integram (panos, tapetes, estantes, cortinas e outros), atuam como fatores primordiais no desenvolvimento da autonomia intelectual e social dos estudantes. 
Em consonância com a Resolução no ${ }^{\circ} 216$ de 15 de setembro de 2004, que dispõe sobre as boas práticas para o serviço de alimentação, bem como da preparação dos alimentos, limpeza, manutenção desses ambientes, as escolas devem se adequar a tais exigências para atender aos princípios legais. Fatores como merenda escolar, cozinhas, refeitórios e cantinas também foram tópicos destacados como relevantes para uma composição de uma estrutura básica escolar de acordo com o PNE (2015).

Em relação à acessibilidade, as unidades escolares precisam pensar a acessibilidade física como um elemento essencial para a promoção da inclusão educacional, tendo em vista a sua responsabilidade em garantir o acesso de todos os alunos, nos mais diversos ambientes da escola, com facilidade, autonomia e segurança.

A acessibilidade pode se apresentar de diversas formas dentro de um espaço escolar, a depender das necessidades da Pessoa com Deficiência. As condições físicas nas escolas de uma forma geral são bem precárias, principalmente, quando essas são construções antigas ou patrimônios históricos onde as modificações são limitadas. Sendo assim, uma unidade escolar pode se deparar com diversas necessidades de adaptação, se possuir um aluno deficiente visual, a escola necessitará de pisos táteis, de avisos em Braille nas entradas; caso o aluno seja deficiente auditivo, a escola precisará do apoio de um intérprete de libras, para realização da tradução, caso o aluno possua deficiência física como cadeirante, banheiros precisam ser adaptados, salas, rampas de acesso terão que ser construídas segundo as normas da Associação Brasileira de Normas Técnicas - ABNT, além do suprimento de outras necessidades estabelecidas por leis como no artigo 227, parágrafos $1^{\circ}$ e $2^{\circ}$ da Constituição Federal, na qual consta que as escolas são obrigadas a oferecer as condições mínimas para àqueles que possuem necessidades especiais, garantindo o direito de igualdade e Art. $8^{\circ}$, que dispõe sobre as Condições Gerais da Acessibilidade (BRASIL, 2004).

Diante das informações que foram apresentadas, observa-se que a infraestrutura exerce influência direta sobre o desenvolvimento educacional. A estrutura em condições ideais atrai e estimula o aluno ao seu crescimento, enquanto em condições insalubres geram desejo de abandono da unidade escolar e queda do rendimento.

Hanushek e Woessman (2017) propõem uma função de produção educacional. Nela a infraestrutura é apenas um bloco do conjunto de fatores que levam ao aprendizado. Também são citados o background familiar, o ambiente institucional e a habilidade individual.

Os desafios apresentados no presente século vêm exigindo cada vez mais dos indivíduos, desde a infância à fase adulta, o desenvolvimento de competências que o auxiliem no alcance do sucesso, seja acadêmico, profissional ou pessoal. Dentro dessa perspectiva, a escola assume um importante papel, como um local privilegiado e facilitador para a aquisição dessas competências primordiais ao desenvolvimento humano. No entanto, esse sucesso educacional não é de exclusividade da escola, a existência de fatores externos como background familiar e social no período de escolarização, está intimamente ligada a essa conquista (SOARES; COLLARES, 2006; SOUZA, 2009). 
Levando em consideração o contexto familiar, muitos estudos protagonizam a família como o principal norteador do aprendizado escolar, influenciando a criança desde a motivação para os estudos, como para o desenvolvimento de competências interpessoais e de relacionamentos, seja com professores ou colegas (BRADLEY, et al., 1988; STEVENSON; BAKER, 1987). Ainda segundo os autores, aspectos como a situação econômica da família, a estrutura do lar, o clima e o envolvimento dos pais na vida escolar do aluno, são fatores de grande relevância ao seu desempenho.

Coleman (1966), em uma pesquisa encomendada pelo governo americano, para 600 mil alunos, intitulada "Equality of educational opportunity" concluiu que o fator causal do desempenho dos alunos, estava relacionado ao perfil familiar e a vizinhança no qual o mesmo está inserido. De acordo com seu estudo, famílias de maior poder aquisitivo, com boa formação, presentes na vida escolar da criança, propiciam melhor desempenho escolar.

Nessa perspectiva, percebe-se que o envolvimento dos pais na vida escolar dos filhos se caracteriza como um fator preponderante ao desenvolvimento acadêmico e educacional dos mesmos (CONNORS; EPSTEIN, 1995; BAKER; STEVENSON; 1987; DEARING et al., 2006).

Por outro lado, Harris (1995) argumenta que a rede de amizades ou relacionamento social desempenha um papel relativamente mais importante do que os pais ou ambiente familiar. Ela acredita que a busca pela aceitação ou inserção em grupos faz com que a criança mude o seu comportamento ou personalidade na tentativa de não ser excluída socialmente, e essa mudança na maioria das vezes se dá na ausência da supervisão dos pais.

Para Patacchini et al. (2011), os amigos são propulsores de interação e motivação no processo de aprendizagem. Um aluno em sala de aula pode desempenhar diversos papéis a depender do contexto ou do grupo que participa, seja influenciando ou sendo influenciado.

Além da rede de amizades e do suporte afetivo e econômico da família, outra variável correlacionada a essas últimas é o efeito territorial. Os territórios são definidos a partir das relações sociais, econômicas e políticas entre os indivíduos, em determinados tipos de espaços ou ambientes, entre eles o entorno escolar (Fonseca e Leal, 2008). Dessa forma, pensar território também é expor os efeitos que dele são produzidos, desde a violência urbana a demais formas de violência no entorno da escola e na vizinhança das moradias dos alunos, que acabam afetando diretamente o seu desempenho de forma negativa.

Discorrer sobre outras influências educacionais e mostrar a relação existente com o processo de aprendizagem do aluno não é algo simples, em virtude da imensidão de variáveis existentes. Entretanto, optou-se por destacar àquelas variáveis de maior influência (positiva ou negativa) para o desempenho educacional do aluno, de acordo com a ênfase dada pela literatura. 


\section{Descrição dos Dados e Metodologia}

Este artigo utiliza o banco de dados gerado pela pesquisa realizada na Fundação Joaquim Nabuco (Fundaj), Intitulada Acompanhamento Longitudinal do Desempenho Escolar de Alunos da Rede Pública de Ensino Fundamental do Recife. A referida pesquisa examinou uma amostra do desempenho dos alunos do $6^{\circ}$ ano do Ensino Fundamental (antiga $5^{\text {a }}$ série) das escolas públicas da cidade do Recife/ Pernambuco, por meio da aplicação de duas provas de matemática elaboradas pela Fundaj (aplicadas ao início do ano de 2013 - Prova 1 e final do ano de 2013 - Prova 2); e quatro tipos de questionários destinados aos alunos, pais ou responsáveis, professores e diretores, permitindo a coleta de uma grande variedade de dados, capazes de expor a realidade educacional das escolas avaliadas e de seus alunos. Ao todo foram pesquisados 4.191 alunos, 3.670 pais ou responsáveis, 120 diretores e 131 professores de 120 escolas espacialmente distribuídas em 6 Regiões Político-Administrativas (RPA's), subdivididas em 18 microrregiões na cidade do Recife. Além dessa fonte de dados, também se fez necessário realizar uma consulta ao Censo Escolar (2013).

Nesse questionário, há uma grande variedade de perguntas sobre infraestrutura feitas, principalmente aos diretores das escolas. Ao contrário do Censo Escolar, a base de dados da Fundaj foi construída a partir de questionários que permitissem captar as impressões da quantidade e da qualidade da infraestrutura das escolas. Para organizar a tabulação dessas informações, dividiram-se as variáveis em três grupos distintos. O primeiro grupo foi denominado "Espaço Pedagógico" e é composto da junção de espaços como salas, bibliotecas, laboratórios, quadras de esportes e auditórios. O segundo grupo, denominado de "instalações de higiene e alimentação", é composto por banheiros, bebedouros, cantinas e refeitórios. Ainda dentro desse grupo, são observados a disponibilização da acessibilidade em banheiros e nas vias de acesso à escola. O terceiro grupo, "computadores e internet", engloba a utilização de computadores e internet para professores e alunos, bem como o uso de outros recursos eletroeletrônicos, como fitas de vídeos, máquinas copiadoras, impressoras, retroprojetor, televisão, antena parabólica, linha telefônica e aparelho de som.

Também foi necessário compatibilizar a base de dados da Fundaj com dados provenientes do Censo Escolar. Agregou-se à base de dados da Fundaj as informações relativas aos serviços de utilidade pública (Abastecimento de água, Energia elétrica, Esgotamento sanitário e Coleta de lixo) que, por existirem no Censo Escolar, não foram levantadas na pesquisa original. O Quadro 1 sumariza as informações das variáveis chave deste artigo. 
Quadro 1 - Categorização das variáveis de Infraestrutura

\begin{tabular}{|ll|}
\hline Blocos & Variáveis \\
& Bibliotecas, \\
II - Espaço Pedagógico & Laboratórios, \\
& Quadras de esportes, \\
& Auditórios \\
III - Computadores de Higiene e Alimentação & Banheiros, \\
& Bebedouros, \\
& Cantinas/Refeitórios \\
& Computadores \\
& Internet \\
Máquinas copiadoras, \\
IV equipamentos & Retroprojetor, \\
& Televisão, \\
& Linha telefônica \\
& Aparelho de som \\
& Abastecimento de água, \\
& Energia elétrica, \\
& Esgotamento sanitário, \\
& Coleta de lixo \\
\hline
\end{tabular}

Fonte: Elaboração do autor a partir dos dados do PNE e Fundaj 2017.

As variáveis dos blocos (I, II, III) apresentadas no Quadro 1, estão estruturadas através de duas medidas de categorias "Quantidade" e "Condições". A primeira está subdividida em "Suficiente, Insuficiente e Inexistente" e a segunda em "Satisfatória, insatisfatória e Sem Uso". Essa estrutura permitiu à pesquisa não apenas a realização de uma análise isolada das referidas categorias, como também o cruzamento entre elas, possibilitando aferir a quantidade e a qualidade dos recursos existentes nas escolas da amostra em estudo, conforme Quadro 2.

Quadro 2 - Cruzamento das medidas "Quantidade x Condições”

\begin{tabular}{|c|c|c|c|}
\hline & QUALIDADE & & \\
\hline QUANTIDADE & Satisfatória & Insatisfatória & Sem Uso \\
\hline Suficiente & $\begin{array}{l}\text { Qtde. Suficiente e Cond. } \\
\text { Satisfatória }\end{array}$ & $\begin{array}{l}\text { Qtde. Suficiente e Cond. } \\
\text { Insatisfatória }\end{array}$ & $\begin{array}{l}\text { Qtde. Suficiente e Cond. } \\
\text { Sem Uso }\end{array}$ \\
\hline Insuficiente & $\begin{array}{l}\text { Qtde. Insuficiente e } \\
\text { Cond. Satisfatória }\end{array}$ & $\begin{array}{l}\text { Qtde. Insuficiente e } \\
\text { Cond. Insatisfatória }\end{array}$ & $\begin{array}{l}\text { Qtde. Insuficiente e Cond. } \\
\text { Sem Uso }\end{array}$ \\
\hline Inexistente & $\begin{array}{l}\text { Qtde. Inexistente e Cond. } \\
\text { Satisfatória }\end{array}$ & $\begin{array}{l}\text { Qtde. Inexistente e Cond. } \\
\text { Insatisfatória }\end{array}$ & $\begin{array}{l}\text { Qtde. Inexistente e Cond. } \\
\text { Sem Uso }\end{array}$ \\
\hline
\end{tabular}

Fonte: Elaboração do autor a partir dos dados Fundaj. 
Após a realização do cruzamento das informações do "Quadro 2", as medidas (Qtde. Inexistente e Cond. Satisfatória, Qtde. Inexistente e Cond. Insatisfatória, Qtde. Inexistente e Cond. Sem Uso) da área não hachurada, retornaram valores igual a zero, tornando o seu uso desnecessário pela ausência de valores. Já para os cruzamentos restantes (área hachurada com graduação de cores) do referido quadro, foram gerados valores superiores a zero, sendo possível a sua análise. No tocante ao termo "Qtde. Inexistente", o mesmo não retornou valores maiores que zero quando cruzados com as demais medidas, sendo necessário analisá-lo de forma isolada. A partir desse ajuste realizado nos cruzamentos, optou-se pela criação de uma escala de medida. Essa escolha se deu por algumas razões, entre elas destaca-se a redução da complexidade dos dados, simplificando a análise, ao combinar muitas variáveis em um único valor de medida, realização de comparações entre variáveis, contribuindo para o desenvolvimento de análises de regressão, bem como o uso de técnicas de correlação estatística, além disso, diminui o erro das mensurações, aumentando a fidedignidade das medidas finais.

Segundo Herrero e Cuesta (2005), a estrutura do processo de medição possui quatro níveis estruturais: 1) variável (propriedade que será medida); 2) o atributo (é o grau em que se comporta a variável - exemplos: bom, médio e ruim); 3) o valor (é a atribuição numérica dada ao grau - exemplos: 1, 2, 3), e 4) relação ("ligação" entre os vários valores da variável).

De acordo com o conceito apresentado, definiu-se como Variável Central: infraestrutura escolar; como Atributo: o cruzamento das medidas (Quadro 2); como Valores: escala de 1 (um) até 7 (sete), crescendo de forma gradual do valor 1 (representando quantidade inexistente), até 7 (para quantidade e condições satisfatórias), conforme apresentado na figura abaixo (Figura 1).

Figura 1 - Definição de valores para os atributos de medição

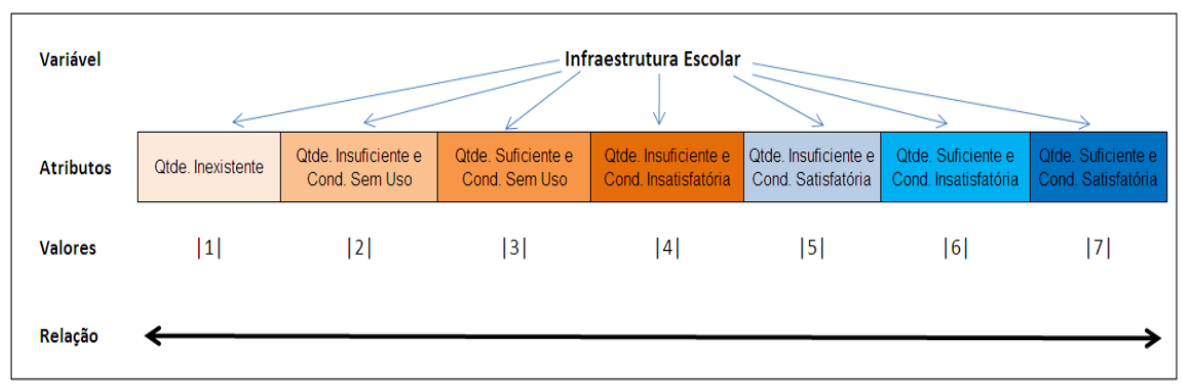

Fonte: Elaboração do autor a partir dos dados Fundaj 2017.

Para além da infraestrutura escolar, também foram selecionadas outras variáveis que de alguma forma influenciaram o aprendizado dos alunos, compreendida nesta pesquisa como "outras influências educacionais", como estrutura familiar, renda, bem como do relacionamento do aluno com os seus pais ou responsáveis. Para seleção 
e definição das variáveis que poderiam compor o bloco "outras influências educacionais" tomou-se como base o Quadro 3 que reproduz tabela de Melo et al.(2017) que utiliza a mesma base de dados que esta pesquisa.

O referido quadro está distribuído em três colunas, sendo a primeira coluna composta pelos construtos, a segunda coluna por sua vez é composta pelas perguntas oriundas dos questionários da pesquisa da Fundaj/2013, e a terceira e última coluna exibe a quantidade de respostas possíveis para cada uma dessas perguntas.

Quadro 3 - Suporte Familiar na Visão do Aluno

\begin{tabular}{|c|c|c|}
\hline Construto & Pergunta & No de categorias \\
\hline \multicolumn{3}{|l|}{ RECURSOS FAMILIARES } \\
\hline \multicolumn{3}{|l|}{ Envolvimento dos Pais } \\
\hline \multirow{5}{*}{$\begin{array}{l}\text { Suporte familiar na visão do } \\
\text { Aluno - SFVA }\end{array}$} & $\begin{array}{l}\text { Quem é a pessoa que acompanha mais de perto sua } \\
\text { vida escolar? }\end{array}$ & 9 \\
\hline & $\begin{array}{l}\text { Seus pais (ou responsável) frequentam as reuniões } \\
\text { escolares? }\end{array}$ & 4 \\
\hline & $\begin{array}{l}\text { Seus pais (ou responsável) conversam sobre o que } \\
\text { acontece na escola com você? }\end{array}$ & 4 \\
\hline & $\begin{array}{l}\text { Seus pais (ou responsável) ajudam você a fazer a } \\
\text { lição de casa? }\end{array}$ & 4 \\
\hline & $\begin{array}{l}\text { Seus pais (ou responsável) cobram se você fez a } \\
\text { lição de casa? }\end{array}$ & 4 \\
\hline \multicolumn{3}{|l|}{ Capital Cultural } \\
\hline \multirow{5}{*}{$\begin{array}{l}\text { Relação com pais na visão do } \\
\text { Aluno - RPA }\end{array}$} & $\begin{array}{l}\text { Quando você faz alguma coisa errada seus pais (ou } \\
\text { responsável) fazem o quê? }\end{array}$ & 6 \\
\hline & $\begin{array}{l}\text { Seus pais (ou responsável) almoçam ou jantam } \\
\text { com você? }\end{array}$ & 4 \\
\hline & $\begin{array}{l}\text { Seus pais (ou responsável) vão ao cinema ou teatro } \\
\text { com você? }\end{array}$ & 4 \\
\hline & $\begin{array}{l}\text { Seus pais (ou responsável) conversam com seus } \\
\text { amigos? }\end{array}$ & 4 \\
\hline & $\begin{array}{l}\text { Seus pais (ou responsável) ajudam você? Ou } \\
\text { estudam com você? }\end{array}$ & 4 \\
\hline
\end{tabular}

Fonte: MELO et al (2017).

Cada um dos construtos apresentados no quadro acima (Relação com pais na visão do Aluno - RPA e Suporte Familiar na Visão do Aluno - SFVA) estão estruturados por questões que exercem uma influência direta no desempenho escolar dos alunos, bem como no seu desenvolvimento intelectual e social (MELO et al., 2017).

No processo de construção da modelagem estatística considerou-se a estrutura das variáveis selecionadas na base de dados, bem como a quantidade de variáveis 
que hipoteticamente exerçam alguma influência no processo de aquisição de conhecimento do aluno. Dessa forma, optou-se pela utilização do modelo econométrico de Regressão Linear Múltipla. Esse modelo parte da suposição da existência de uma relação linear entre o valor médio de uma variável y (variável dependente) e K variáveis (variável independente ou explicativa).

Dado o objetivo central deste trabalho, que é analisar o efeito da infraestrutura sobre o processo de aprendizagem do aluno, o seguinte modelo foi estimado:

$$
Y=\beta_{0}+\beta_{1} X_{1}+\beta_{2} X_{2}+\beta_{3} X_{3}+\beta_{4} X_{4}+\mu
$$

Em que:

$$
\begin{aligned}
& Y=\text { Nota } 2 \text { (variável dependente); } \\
& X_{1}=\text { Nota } 1 \text { (variável independente); } \\
& X_{2}=\text { Espaço Pedagógico; } \\
& X_{3}=\text { Instalações de Higiene e Alimentação; } \\
& X_{4}=\text { Computadores, Internet e Equipamentos. }
\end{aligned}
$$

Esta aplicação se deu com objetivo de se compreender como a variável dependente (), Nota 2, reagia sobre o efeito da infraestrutura (. De acordo com Ding e Lehrer (2007), a nota inicial (Nota 1) quando inserida no modelo de regressão, além de se tornar uma proxy valiosíssima, capturando a história pregressa do aluno e de seu contexto social, ela também tenta corrigir eventuais problemas de endogeneidade no modelo de regressão.

Além dessas variáveis centrais, também foram utilizadas variáveis que contemplem outros aspectos do desempenho escolar dos alunos, conforme foi detalhado no referencial teórico. De acordo com o levantamento bibliográfico realizado, as novas variáveis a serem incluídas na estimação do modelo está relacionada às outras influências educacionais, ou seja, renda, suporte familiar ou informações sociodemográficas dos alunos. Sendo assim, as variáveis selecionadas para se verificar o que de fato vem influenciando o processo de aprendizagem dos alunos e que também servirão para a construção do modelo econométrico estão relacionadas no Quadro 4.

Para construir a variável Suporte Familiar, foram agrupados os construtos SFVA (Suporte Familiar na Visão do Aluno) e RPA (Relação com os Pais na Visão dos Alunos). Quando SFVA e RPA pertenciam à categoria "Grupo alto" a variável suporte familiar recebia a categorização "alto", do contrário, era categorizada como "baixo". As variáveis, Raça/Cor e Quantidade de Quartos, também receberam o mesmo tratamento, com exceção apenas para a idade.

Quando os alunos forem de Raça/Cor não-branca ”, e quando for branca. Já para a Quantidade de Quartos, a variável assume valor “1” quando o aluno possuir dois quartos ou mais em sua residência e " 0 " se possuir 1 quarto ou nenhum. 
Essas variáveis dummies foram utilizadas com o intuito de observar o comportamento escolar do aluno, quando combinadas a outras variáveis independentes, buscando uma estimação menos enviesada para o modelo, foi possível chegar à seguinte estimação:

$$
\begin{aligned}
& Y=\beta_{0}+\beta_{1} X_{1}+\beta_{2} X_{2}+\beta_{3} X_{3}+\beta_{4} X_{4}+\beta_{5} X_{5}+\beta_{6} C_{1}+\beta_{7} C_{2}+\beta_{8} C_{3}+\beta_{9}\left(X_{1}\right)^{2}+ \\
& \beta_{10} X_{1} X_{5}+\beta_{11}\left(X_{1}\right)^{2} X_{5}+\beta_{12} X_{1} X_{4}+\beta_{13} C_{1} X_{2}+\beta_{14} X_{2} X_{3}+\beta_{15} X_{2} C_{2}+\varepsilon
\end{aligned}
$$

Quadro 4 - Descrição das variáveis usadas no modelo econométrico

\begin{tabular}{|ll|}
\hline Variável & Descrição \\
Nota 2() & Variável dependente, segunda prova realizada ao fim do ano \\
Nota 1 & Variável independente, primeira prova realizada no início do ano \\
Espaço Pedagógico & Bibliotecas, Laboratórios, Quadras de esportes, Auditórios \\
Instalações de Higiene e & Banheiros, Bebedouros, Cantinas/Refeitórios \\
Alimentação & Computadores, Internet, Máquinas copiadoras, Impressoras, \\
Computadores, Internet e & Retroprojetor, Televisão, Linha telefônica Aparelho de som \\
Equipamentos & Variável que representa a idade do indivíduo \\
Idade & $\begin{array}{l}\text { Variável dummy SFVA e RPA que assume valor } 1 \text { quando o suporte } \\
\text { familiar na visão do aluno é baixo e } 0 \text { quando for alto. } \\
\text { Suporte Familiar }\end{array}$ \\
O suporte familiar na visão do aluno é alto, se só se, SFVA e RPA \\
forem altos, caso contrário, será considerado baixo. \\
Quariável dummy que assume valor 1 quando o aluno possui dois \\
quartos ou mais em casa e 0 se possuir 1 quarto ou nenhum. \\
Raça
\end{tabular}

Fonte: Elaboração dos autores a partir dos dados da Fundaj.

A referida estimação foi realizada em primeiro momento através da aplicação de uma equação de Regressão Linear Múltipla (Mínimos Quadrados Ordinários). No segundo momento, uma análise gráfica foi feita buscando entender a relação entre as variáveis explicativas e a variável resposta, resultando em um modelo com 38 parâmetros.

Por fim, o método de seleção de variáveis (algoritmo Stepwise ${ }^{4}$ ) utilizando o critério de informação de $\boldsymbol{A} \boldsymbol{k a i k} \boldsymbol{e}^{5}$ (AIC) foi utilizado a fim de reduzir a dimensão do modelo, o que resultou no modelo final com o total de 16 parâmetros.

4 Stepwise: No algoritmo Stepwise um teste F é utilizado, para seleção ou exclusão de variáveis de um modelo, verificando a importância das mesmas, por meio da sua significância estatística. Fonte: http:// www.portalaction.com.br/analise-de-regressao/4251-selecao-stepwise.

5 Akaike(AIC):. O critério de informação de Akaike (AIC) desenvolvido a partir a distância de Kullback-Leibler (K-L), a qual é uma distância entre o modelo verdadeiro, que geralmente é uma abstração, e o modelo candidato, possui a finalidade de aproximar o modelo estimado o mais próximo da realidade. Fonte: http://www2.dbd.puc-rio.br/pergamum/tesesabertas/0621277_10_cap_05.pdf. 


\section{Resultados}

Uma vez especificado o modelo e definidas as variáveis, esta seção se destina em apresentar, por meio de gráficos e tabelas, as estatísticas relacionadas à infraestrutura das escolas, destacando como elas estão equipadas em termos de espaço físico e dos serviços de utilidade pública disponíveis nesses locais. Em seguida, serão demonstrados os resultados finais das estimativas do modelo, bem como das interações entre as variáveis estudadas.

O primeiro gráfico dessa seção (Gráfico I) apresenta o percentual médio de informações sobre a quantidade/qualidade das bibliotecas, laboratórios, quadra de esportes e auditório (Bloco - Espaço Pedagógico). Observando o gráfico e os valores em destaque, é possível perceber que no tocante à medida "Quantidade Suficiente/Condições Satisfatórias" as variáveis: Biblioteca, Laboratórios, Quadra esportiva e Auditório, apresentaram valores bem diferenciados. Cerca de 68,05\% dos alunos da amostra em análise estudam em escolas nas quais os diretores declararam que a quantidade de bibliotecas são suficientes e a qualidades delas são satisfatórias; essa mesma medida também se aplica à variável laboratórios, em que 39,20\% dos entrevistados informaram que tanto o laboratório de ciências como o de informática possuem quantidades suficientes com qualidades satisfatórias. Já para as variáveis Quadra esportiva e Auditório respectivamente, à medida em que o destaque foi "Quantidade Insuficiente/Condições Insatisfatórias”, com 30,97\% para quadras esportivas e 26,49\% para auditórios.

Gráfico 1 - Percentual dos alunos que estudam em escolas onde os diretores declararam a situação do Espaço Pedagógico (Bloco I)

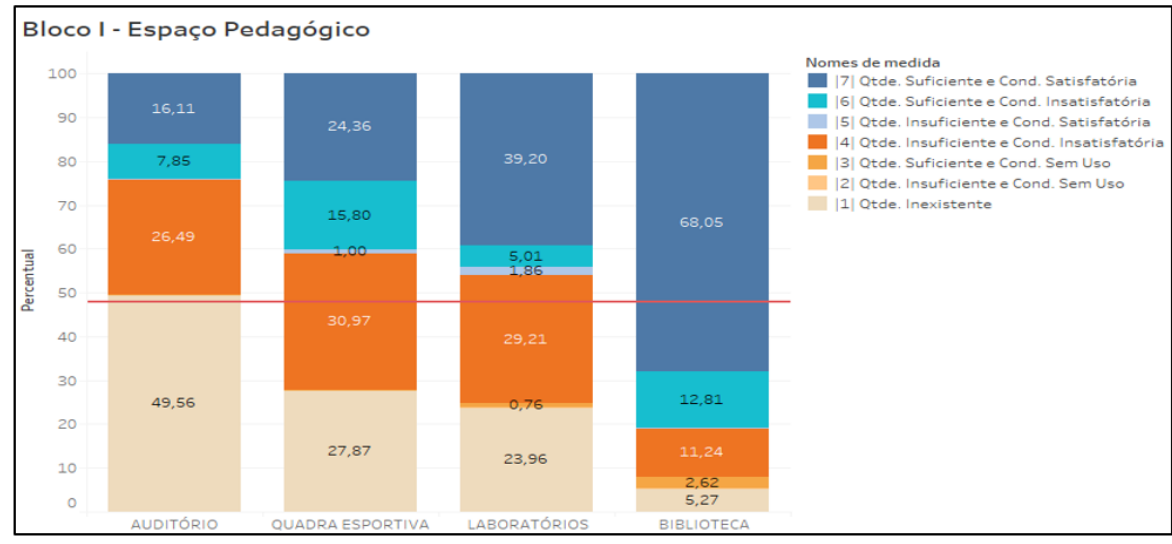

Fonte: Elaboração do autor a partir dos dados da Fundaj. 
Esses resultados apresentados, positivos para as variáveis "bibliotecas" e "laboratórios", e os negativos para "auditórios" e "quadras", coincidem com as decisões tomadas pela política pública educacional do Pacto Pela Educação - PPE (2009) que teve por objetivo inicial priorizar a recuperação dos espaços físicos das escolas sucateadas, com ênfase na disponibilização de equipamentos como bibliotecas e laboratórios (ciências e informática), buscando atender a um padrão mínimo de funcionamento escolar (SEPLAG, 2011).

Também é possível identificar de acordo com o gráfico, a partir da sua linha mediana, que aproximadamente 50\% dos alunos da Rede Pública (Municipal e Estadual) da RMR, possuem os quatro espaços pedagógicos (biblioteca, laboratórios, quadra esportiva e auditório), ainda que essas condições sejam insatisfatórias com quantidades insuficientes como é o caso dos auditórios e quadras, onde 49,56\% e 27,87\% respectivamente, inexistem nas dependências da escola.

O gráfico 2, por sua vez, estruturado pelo Bloco - Instalações de Higiene e Alimentação (banheiros, bebedouros, cantinas/refeitórios), revela que 18,97\% dos alunos possuem quantidades insuficientes de banheiros e que as condições de uso desses são insatisfatórias. Ou seja, um percentual razoável das escolas não é provido de uma quantidade satisfatória desse equipamento em condições adequadas. Considerando que se tratam de instalações básicas, esse percentual ainda é considerado alto, em virtude de sua grande utilidade no ambiente escolar, tanto por parte dos alunos como dos professores. A presença de bebedouros também é expressiva, embora 22,67\% considerem que a quantidade e as condições ainda são insuficientes nas escolas. No tocante a variável cantinas/refeitórios, o referido gráfico apontou que 49,77\% possuem instalações desse tipo, em condições satisfatórias e em quantidades suficientes e apenas 17,37\% informaram que não, ou seja, as quantidades/condições são sim, insuficientes e insatisfatórias.

Gráfico 2 - Percentual dos alunos que estudam em escolas onde os diretores declararam a situação das instalações de higiene e alimentação (Bloco II)

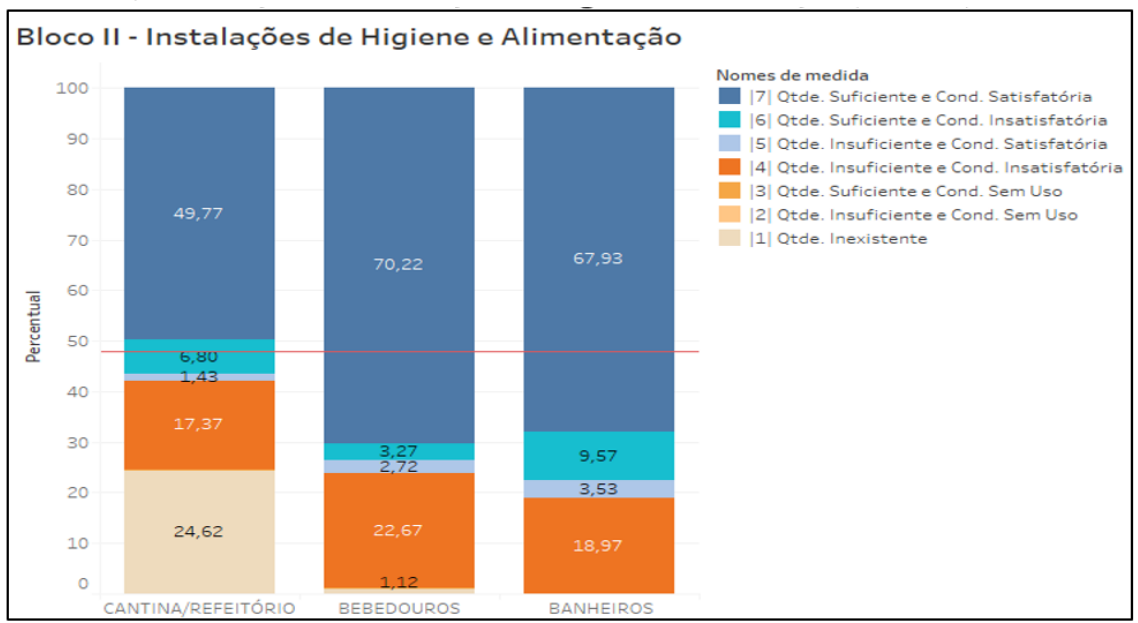

Fonte: Elaboração do autor a partir dos dados da Fundaj. 
De acordo com a Resolução $\mathrm{n}^{\circ}$. 216 de 15 de setembro de 2004, que dispõe sobre as boas práticas para o serviço de alimentação, bem como da preparação dos alimentos, limpeza, manutenção desses ambientes, as escolas devem se adequar a tais exigências para atender aos princípios legais. Fatores como merenda escolar, cozinhas, refeitórios e cantinas também foram tópicos destacados como relevantes para uma composição de uma estrutura básica escolar de acordo com o Censo Escolar (2006).

Mesmo sendo alvo de legislações, por se tratar de um requisito básico na composição da estrutura escolar, os referidos equipamentos ainda carecem de muita atenção por parte dos formuladores das políticas públicas no quesito melhoria da qualidade, pois o que se percebe é uma grande preocupação em oferecer o espaço, mas pouco esforço para mantê-lo nas condições de uso.

Os gráficos seguintes (Gráfico 3 e Gráfico 4) relacionam as variáveis contidas no BLOCO III (Computadores, Internet, Máquinas copiadoras, Impressoras, Retroprojetor, Televisão, Linha telefônica, Aparelho de som). Para melhor compreensão, as variáveis foram separadas em dois grupos distintos, sendo o primeiro compreendido por computadores e internet e o segundo por equipamentos. É importante ressaltar que a disponibilização desses equipamentos eletrônicos dentro do ambiente escolar tem o objetivo de auxiliar o aluno em seu processo de aprendizado, ilustrando os conhecimentos teóricos de uma maneira mais interativa e prática, gerando uma alternativa adicional à figura do professor na transmissão de informações e conhecimentos para os alunos (FUNDAJ, 2009, p.34).

O Gráfico 3, compreendido pelo primeiro grupo, traz a disponibilidade de computadores e internet tanto para uso dos alunos como para os professores, e os resultados apresentados mostram que as variáveis (acesso à internet e uso dos computadores) tiveram quantidades insatisfatórias com condições insuficientes em todos os seus itens, com exceção apenas para a variável "computadores para uso administrativo", com quantidades/qualidades acima de $50 \%$.

Gráfico 3: Percentual dos alunos que estudam em escolas onde os diretores declararam possuir computadores e internet (Bloco III)

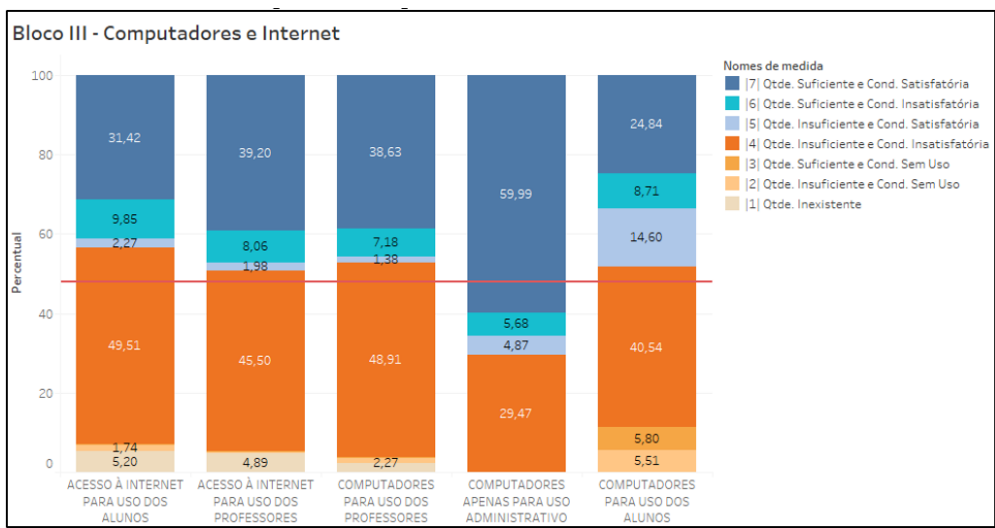

Fonte: Elaboração do autor a partir dos dados da Fundaj. 
Por sua vez, no Gráfico 4, composto pelo grupo dos equipamentos, verificou-se que todos os itens elencados tiveram quantidades satisfatórias e condições suficientes, ou seja, é comum a presença de máquinas copiadoras, impressoras, DVD’s, TV’s e demais equipamentos em condições de usabilidade no ambiente escolar como apresenta o gráfico abaixo.

Gráfico 4: Percentual dos alunos que estudam em escolas onde os diretores declararam possuir equipamentos eletrônicos (Bloco III)

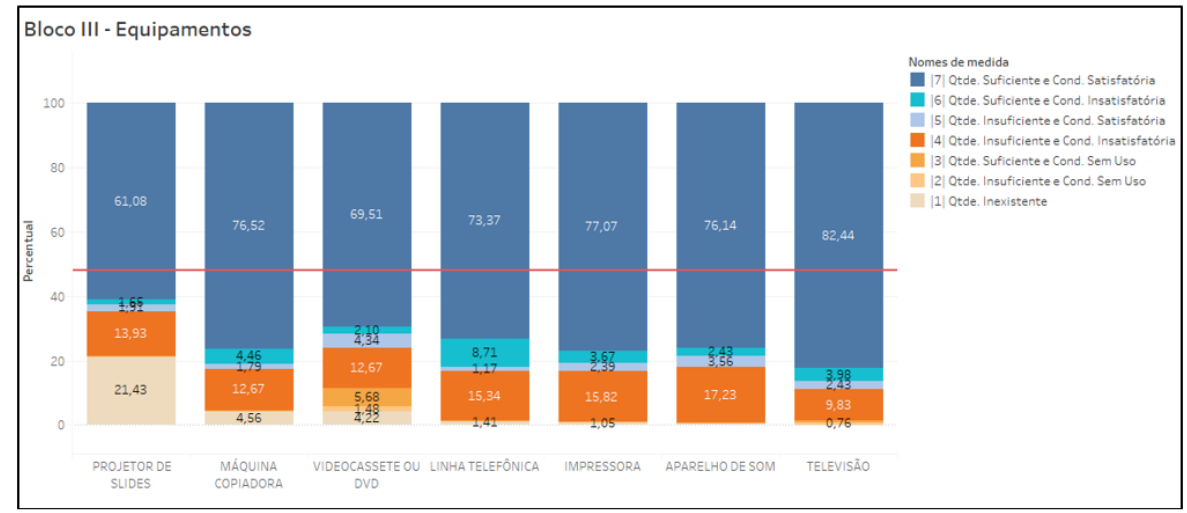

Fonte: Elaboração do autor a partir dos dados da Fundaj.

Por fim, no último bloco (serviços de utilidade pública) relacionado às variáveis de infraestrutura escolar, Gráfico 5, buscou-se avaliar através do cruzamento realizado com o CENSO/2013, a existência ou não de serviços como abastecimento de água encanada e filtrada, energia elétrica, esgoto sanitário e coleta de lixo, nas escolas da Rede Pública.

Gráfico 5: Cruzamento dados Fundaj/2013 e Censo/2013 (Bloco IV)

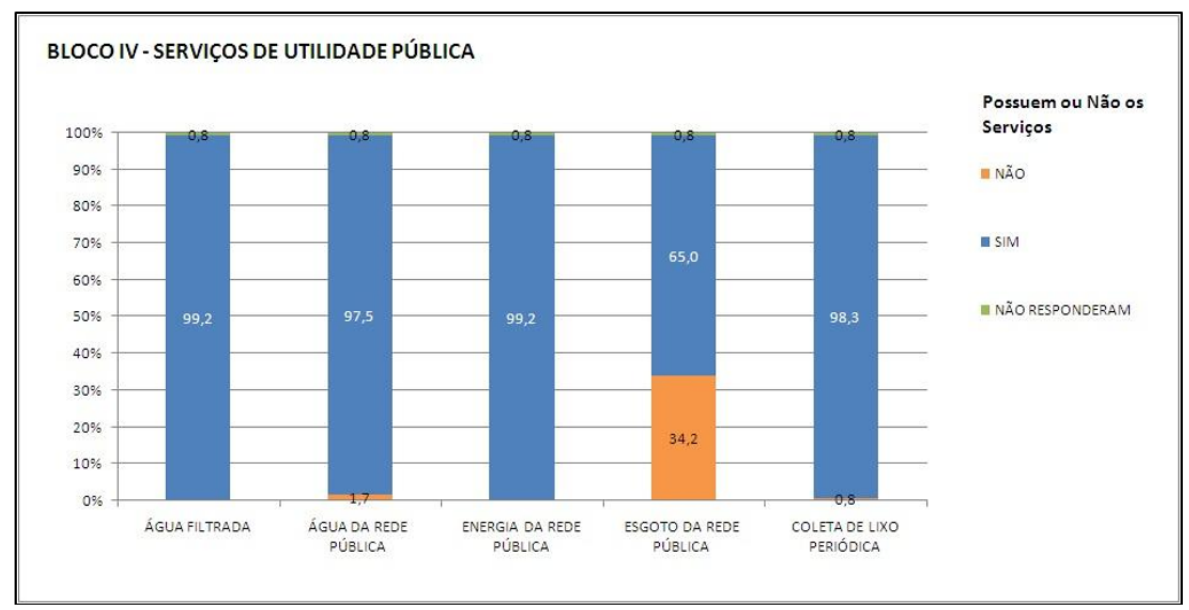

Fonte: Elaboração do autor a partir dos dados da Fundaj. 
O que se pôde perceber, por meio do gráfico acima, é que do total das 120 escolas da amostra, quase $100 \%$ delas desfrutam, em suas dependências, dos serviços básicos de utilidade pública, ou seja, dispõem de abastecimento de água encanada e filtrada, energia elétrica e coleta de lixo, com exceção apenas da variável "Esgoto da Rede Pública”, em que 34,2\% escolas afirmaram não possuir acesso à rede pública de esgoto. Esse último dado destaca uma realidade um pouco preocupante, em virtude de ser uma área urbana e não rural, onde os recursos são mais acessíveis de um modo geral e possuem uma estrutura político-administrativa mais organizada.

No tocante às informações relativas a outras influências educacionais, como estrutura familiar do aluno, o perfil socioeconômico do mesmo e de como essas varáveis afetam o seu desempenho escolar, investigou-se a relação do suporte familiar na perspectiva do aluno.

De acordo com os dados apresentados na pesquisa, "A medida do capital cultural familiar no desempenho escolar", a presença materna é a figura familiar mais presente na vida do aluno, seja em um contexto de alto suporte familiar (Grupo Alto - GA) ${ }^{6}$, com $86 \%$ de participação, ou com suporte familiar menos favorável (Grupo Baixo - GB), com 78,5\%. Em ambos os casos, a mãe é a representante mais frequente.

Embora a diferença de valores entre os alunos com alto e baixo suporte familiar não seja expressiva, o Grupo Alto (GA) registrou percentuais mais elevados para a opção "sempre ou quase sempre" nas respostas dadas pelo estudante em relação à participação da mãe, ou seja, mães do Grupo Alto, sempre ou quase sempre, frequentam as reuniões escolares, conversam sobre o que acontece na escola e ajudam os filhos a fazer a lição de casa. Essa mesma proporção se torna inversa quando se trata da participação dos pais na vida escolar do aluno, em que eles "nunca ou quase nunca” podem estar presentes, na visão dos alunos.

Referente ao perfil dos alunos e ao percentual médio dos que compõe a amostra, o Quadro 5, a seguir, destacou que 51\% dos estudantes são do sexo masculino, $61,8 \%$ se declararam pardos e 51,5\% estão no $6^{\circ}$ ano do Ensino Fundamental com idade de 11 anos, idade adequada para esta série.

6 5Grupo Alto - GA: Concentra estudantes com uma situação mais elevada tanto de acompanhamento nos estudos, quanto de relação com os pais ou responsáveis, com $55,35 \%$;

Grupo Baixo - GB: Concentra os alunos com uma situação menos favorável, inversa ao GA, com 44,64\%. Fonte: A medida do capital cultural familiar no desempenho escolar. $18^{\circ}$ Congresso Brasileiro de Sociologia, 2017, Brasília 
Quadro 5: Perfil dos Alunos por Idades, Cor/Raça e Gênero

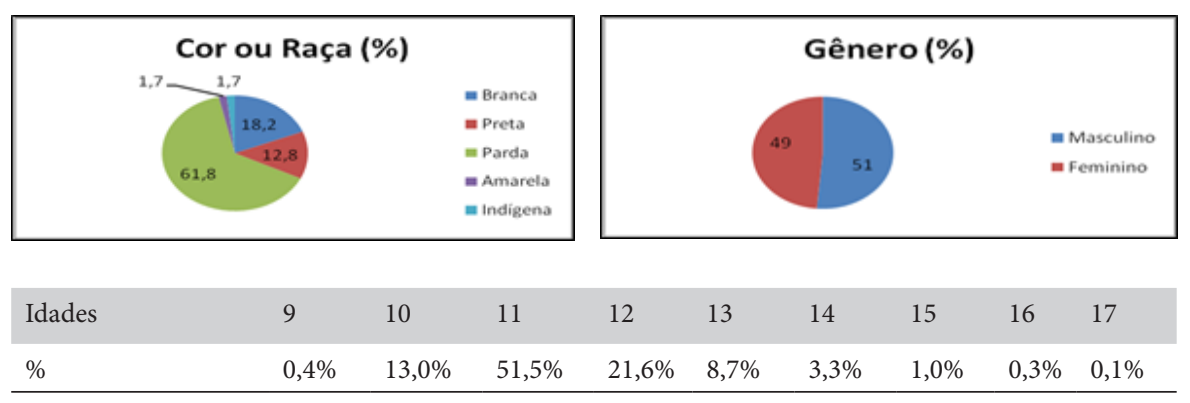

Fonte: Elaboração do autor a partir dos dados da Fundaj.

Para avaliar a situação socioeconômica da vida do aluno, foi realizado o teste t-student para comparação das médias de cada variável apresentada no Quadro 6. Dentre as variáveis que apresentaram maior significância estatística destacaram-se: "quantidade de quartos" e se o aluno "possui ou não empregada doméstica”. Após a identificação dessas variáveis, um processo de estimação foi feito utilizando cada uma delas como proxy do nível socioeconômico, retornando com o melhor resultado "quantidade de quartos", sendo esta a variável escolhida.

Ao analisar a referida variável de acordo com Gráfico 6, observa-se que apenas pouco mais de $50 \%$ dos alunos dispõem de dois quartos em sua residência, e 13,9\% ainda dividem o quarto com outros membros da família. Em razão de estarmos falando de um quesito básico, em uma região relativamente desenvolvida e urbanizada (Recife), tal informação tem impacto preocupante não apenas na vida dessa família, como também e principalmente no processo de formação e aprendizado desse aluno.

Gráfico 6 - Quantidade de quartos por domicílio (\%)

\section{Quantidade \%}

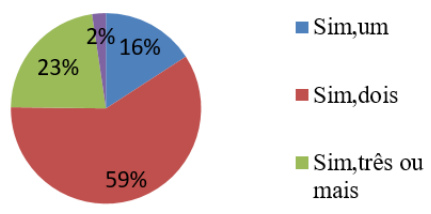

Fonte: Elaboração do autor a partir dos dados da Fundaj.

Os resultados da regressão com o melhor ajustamento são relatados na Tabela 1. Algumas variáveis foram mantidas mesmo sem apresentarem testes $t$ significativos porque apresentam interações com outras variáveis significantes, não fazendo sentido desconsiderá-las. A raça/cor foi mantida por ser variável de descrição do aluno que, se analisada sem variáveis de controle, tende a apresentar significância com a nota. 
Tabela 1 - Resultados da regressão

\begin{tabular}{|c|c|c|c|c|}
\hline Variável & Estimativas & $\begin{array}{l}\text { Desvio } \\
\text { Padrão }\end{array}$ & Estatística t & p-valor \\
\hline Intercepto & 76,799 & 9,245 & 8,31 & 0,000 \\
\hline Nota 1 & $-1,338$ & 0,364 & $-3,68$ & 0,000 \\
\hline Espaço pedagógico & $-3,121$ & 0,896 & $-3,48$ & 0,001 \\
\hline Espaço de higiene e alimentação & $-2,209$ & 0,612 & $-3,61$ & 0,000 \\
\hline Espaço de informática e equipamentos & $-1,194$ & 0,867 & $-1,38$ & 0,169 \\
\hline Idade & $-2,262$ & 0,553 & $-4,09$ & 0,000 \\
\hline Suporte familiar & 3,557 & 1,463 & 2,43 & 0,015 \\
\hline Quantidade de quartos & $-3,189$ & 1,859 & $-1,72$ & 0,086 \\
\hline$(\text { Nota } 1)^{2}$ & 0,025 & 0,005 & 5,26 & 0,000 \\
\hline Raça/Cor & 0,324 & 0,599 & 0,54 & 0,589 \\
\hline $\operatorname{Idade}^{\star}(\text { Nota } 1)^{2}$ & $-0,002$ & 0,000 & $-3,99$ & 0,000 \\
\hline$(\text { Nota } 1)^{*}$ (Espaço de informática e equipamentos) & 0,050 & 0,020 & 2,54 & 0,011 \\
\hline$(\text { Nota } 1)^{\star}($ Idade $)$ & 0,088 & 0,030 & 2,89 & 0,004 \\
\hline $\begin{array}{l}(\text { Espaço pedagógico })^{*}(\text { Espaço de higiene e } \\
\text { alimentação })\end{array}$ & 0,436 & 0,141 & 3,10 & 0,002 \\
\hline$(\text { Espaço pedagógico })^{*}($ Suporte familiar $)$ & $-0,652$ & 0,304 & $-2,14$ & 0,032 \\
\hline$(\text { Espaço pedagógico })^{\star}$ (Quantidade de quartos) & 0,945 & 0,389 & 2,43 & 0,015 \\
\hline \multicolumn{5}{|l|}{ Desvio padrão dos resíduos $=13,228$} \\
\hline \multicolumn{5}{|l|}{$\mathrm{R}^{2}=32,62 \%$} \\
\hline \multicolumn{5}{|l|}{$\mathrm{R}^{2}$ ajustado $=32,29 \%$} \\
\hline \multicolumn{5}{|l|}{ Estatística $F=102,195$ e p-valor $=0$} \\
\hline G.L. dos resíduos = 3167 & & & & \\
\hline
\end{tabular}

Fonte: Elaboração do autor a partir de dados da Fundaj.

A nota 1 (primeira avaliação) possui uma relação polinomial com a nota 2 (segunda avaliação) e de formato côncavo, ou seja, para quem tirou notas baixas na nota 1 a tendência é que a nota 2 não mude muito, mas, à medida que a nota na primeira avaliação aumenta, a segunda nota tende a diminuir. Essa relação se torna ainda mais evidente quando a idade do aluno é avançada (alunos que se encontram em situação de distorção idade-série), já que a variável Idade faz produto com o termo linear e quadrático da Nota1. Além disso, o termo linear da Nota1 ainda possui um cruzamento com o bloco de infraestrutura referente aos equipamentos de informática, o que diminui essa defasagem. Dessa maneira, para medir o efeito individual das variáveis explicativas em relação à Nota 2 calculou-se o efeito marginal dos dados. Para a nota 1 obteve-se: 


$$
\frac{\partial y}{\partial x_{1}}=-1,338+0,05 x_{4}+0,05 x_{1}-0,004 x_{1} x_{5}+0,088 x_{5}
$$

Considerando que as médias para 1, 4 e 5 são respectivamente 42,339; 5,796 e 11,325 , e aplicando-se os referidos valores na equação acima, se obteve como resultado 0,1472433 , ou seja, na média o efeito marginal da Nota 1 sobre o desempenho final do aluno (Nota 2) é positivo.

Já para o produto do termo linear da notal com o bloco de equipamentos de informática, têm-se que:

$$
\frac{\partial^{2} y}{\partial x_{1} \partial x_{4}}=0,05
$$

Assim, observa-se que independentemente da idade ou Nota 1, quanto melhor for a infraestrutura melhor será a Nota 2. Entretanto, observa-se que o investimento em equipamentos de informática diminui o efeito negativo do background escolar (bagagem pregressa do aluno antes da primeira prova).

Para a idade, tem-se que,

$$
\frac{\partial y}{\partial x_{5}}=-0,002 x_{1}^{2}+0,088 x_{1}-2,262 \Rightarrow \frac{\partial x_{5}}{\partial y}<0, \forall x_{1}
$$

A relação da idade com a nota 2 , forma uma parábola em função da nota 1 , sendo assim, como a nota 1 varia de 0 a 100 a derivada nunca irá alcançar valores positivos. Através do gráfico abaixo é fácil ver esse resultado:

Gráfico 7 -Variação da Idade com Nota 2

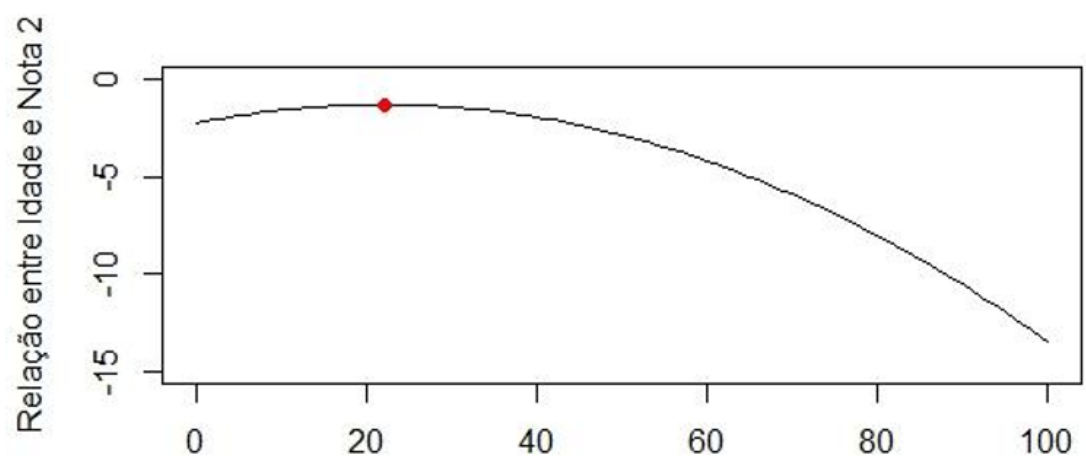

Nota 1

Fonte: Elaboração do autor a partir dos dados da Fundaj. Programa R-Studio 3.4.1 
Dentre as variáveis de infraestrutura (Espaço Pedagógico, Higiene e Alimentação e Equipamento de Informática) todas apresentam estimativas positivas, quando interagem com alguma outra variável explicativa (Suporte Familiar, Renda e Nota 1), sendo assim, o efeito individual de cada variável de infraestrutura está condicionado a alguma outra variável. Computando as derivadas parciais tem-se:

$$
\begin{gathered}
\frac{\partial y}{\partial x_{2}}=-3,097+0,44 x_{3}+0,915 c_{2}-0,682 c_{1} \\
\frac{\partial y}{\partial x_{3}}=-2,254+0,44 x_{2} \\
\frac{\partial y}{\partial x_{4}}=-1,646+0,061 x_{1}
\end{gathered}
$$

Verifica-se para o bloco de espaço pedagógico () que para o acréscimo de uma unidade desta variável o desempenho do aluno abaixa em -3,097, contudo, esse efeito pode mudar de acordo com as outras variáveis. Para esta análise a seguinte inequação será estudada:

$$
\frac{\partial y}{\partial x_{2}}>0
$$

O que implica:

$$
x_{3}>\frac{0,682 c_{1}-0,915 c_{2}+3,097}{0,44}
$$

Sendo assim, a desigualdade vale se:

$$
\begin{aligned}
& c_{1}=1 \mathrm{e} c_{2}=1 \rightarrow x_{3}>6,509(a) \\
& c_{1}=1 \mathrm{e} c_{2}=0 \rightarrow x_{3}>8,587 \\
& c_{1}=0 \mathrm{e} c_{2}=0 \rightarrow x_{3}>7,038 \\
& c_{1}=0 \mathrm{e} c_{2}=1 \rightarrow x_{3}>4.959(b)
\end{aligned}
$$

Logo, para os casos (a) e (b), quão melhor for à estrutura referente ao espaço pedagógico, ou seja, quanto melhor forem as bibliotecas, os laboratórios, auditórios e quadras esportivas, maiores serão os resultados no desempenho do aluno na Nota 2. 
Entretanto, observa-se para o caso (a), os alunos com baixo suporte familiar e melhor situação econômica somente vão se beneficiar da melhoria do espaço pedagógico se já estiverem com boa infraestrutura de Higiene e Alimentação. Já para os demais casos, o que se percebe é que alunos com baixa renda não usufruem do espaço como os demais dos casos $a$ e $b$.

Para o bloco das instalações de Higiene e Alimentação, a interpretação é similar, mas agora o efeito negativo de Higiene e Alimentação ( é reduzido por Espaço Pedagógico , ou seja, para que os espaços de Higiene e Alimentação influenciem positivamente o desempenho dos alunos se faz necessário que haja um investimento em paralelo no Espaço Pedagógico escolar, demonstrando a necessidade de melhoria simultânea nos equipamentos de infraestrutura e não apenas de maneira isolada.

$$
\frac{\partial y}{\partial x_{3}}>0 \text { se, e somente se, } x_{2}>5,122
$$

Dessa maneira, as instalações de higiene e alimentação terão efeito positivo sobre o desempenho do aluno caso o espaço pedagógico alcance valores maiores que 5,122.

Já para o bloco dos equipamentos de informática (Computadores, Internet, máquinas copiadoras, TV, Telefones e impressoras), à medida que a Nota 1 aumenta, o investimento nesses equipamentos aumenta o resultado da Nota 2. Daí segue-se para análise de:

$$
\frac{\partial y}{\partial x_{4}}>0 \Rightarrow-1,194+0,05 x_{1}>0
$$

Onde, a desigualdade é verdade quando:

$$
x_{1}>27,035
$$

Sendo assim, quando o aluno atinge Nota 1 maior que 27,035 o efeito referente aos equipamentos de informática e seus derivados sobre o desempenho final (Nota 2) do aluno torna-se positivo.

Realizando o procedimento anterior para as variáveis categóricas temos o seguinte resultado:

$$
\begin{gathered}
\frac{\partial y}{\partial c_{1}}=3,747-0,682 x_{2} \text { se } c_{1}=1 \\
\frac{\partial y}{\partial c_{2}}=-2,966+0,915 x_{2} \text { se } c_{2}=1 \\
\frac{\partial y}{\partial c_{3}}=0,243 \text { se } c_{3}=1
\end{gathered}
$$


Se o aluno possui um suporte familiar baixo então, o intercepto será acrescido de 3,747, entretanto, como ela faz produto com , seu efeito não será positivo e sim negativo. Além disso, seu efeito é amplificado a depender do espaço pedagógico oferecido pela escola. Assim, compreende-se que ainda que o aluno estude em uma escola com uma infraestrutura equipada, esse, caso possua um baixo suporte familiar, não irá usufruir dos mesmos, gerando um impacto negativo em seu desempenho acadêmico e consequentemente em sua avaliação final.

No tocante à variável Renda, têm-se que quando o número de quartos da moradia do aluno é maior ou igual a dois, a Nota 2 do aluno é aumentada a partir de valores maiores que 3,24 obtidos na primeira avaliação. Ou seja, alunos que possuem uma boa situação econômica familiar tendem a apresentar um melhor desempenho na segunda nota. Já para alunos de raça/cor não branca a nota na avaliação 2 aumenta em 0,243, contudo, este aumento não é significativo ( $\mathrm{p}$-valor $=0,59)$.

\section{Notas Conclusivas}

O presente estudo teve por objetivo analisar até que ponto a infraestrutura escolar afeta o desempenho dos alunos, a partir do caso particular da rede pública de ensino do Recife. Com esses resultados, pretende-se contribuir para a continuidade das pesquisas sobre o papel da infraestrutura escolar no processo de aprendizagem do aluno, bem como servir de evidência empírica para gestores públicos no processo de formulação das políticas públicas educacionais. Embora não haja um consenso por parte da literatura, o estudo realizado por meio da meta-análise indica que a infraestrutura escolar se constitui como uma ferramenta importante para o desenvolvimento escolar dos alunos.

Para o alcance desse objetivo, foram estruturados três novos blocos de variáveis relacionadas à infraestrutura escolar (Bloco I - Espaço pedagógico; Bloco II - Instalações de higiene e alimentação; Bloco III - Computadores e internet). Após a estruturação das variáveis, as análises foram divididas em três momentos: em primeiro lugar, foi observado por meio da estatística descritiva à situação da infraestrutura das 131 escolas, o suporte familiar e por fim o perfil socioeconômico e sociodemográfico desses estudantes. $\mathrm{Na}$ sequência, foi tratada a relação do ganho de conhecimento do aluno sobre o efeito da infraestrutura, através da aplicação de uma equação de Regressão Linear Múltipla (Mínimos Quadrados Ordinários). No terceiro momento, uma análise gráfica foi feita, buscando entender a relação entre as variáveis explicativas e a variável resposta, o que resultou em nosso modelo final com o total de 16 parâmetros.

Os resultados mostram que o indicador de infraestrutura apresenta estimativas positivas, quando interagem com alguma outra variável explicativa (Suporte Familiar e Renda), sendo assim, o efeito individual dos blocos I, II e III de infraestrutura está condicionado a outras variáveis. Esses resultados corroboram o estudo realizado por Coleman (1966), "Equality of educational opportunity", chegando à conclusão de que o fator causal do desempenho dos alunos estava relacionado ao perfil familiar. De acordo com seu estudo, famílias de maior poder aquisitivo, com boa formação, presentes na vida escolar da criança, propiciam melhor aproveitamento do espaço escolar, inclusive da infraestrutura. 
Ao avaliar a influência do Espaço Pedagógico no rendimento escolar dos alunos, verificou-se que esses espaços só influenciam positivamente o estudante quando este, em primeiro lugar, dispõe de uma condição financeira mais elevada e; em seguida, possua um bom suporte familiar. Quando essas condições são atendidas (suporte familiar alto e condições financeiras elevadas) os equipamentos de bibliotecas, laboratórios, quadras de esportes e auditórios, influenciam positivamente o desempenho escolar do aluno. Do contrário,suporte familiar baixo e condições financeiras inferiores), ainda que a escola oferte tais espaços o aproveitamento por parte desse aluno será defasado, quando comparado à primeira situação.

No tocante às Instalações de Higiene e Alimentação, observa-se uma relação de interdependência com o Espaço Pedagógico, ou seja, para que os espaços de Higiene e Alimentação (Banheiros, Bebedouros, Cantinas/Refeitórios) influenciem positivamente o desempenho dos alunos, se faz necessário que haja um investimento em paralelo no Espaço Pedagógico escolar, demonstrando a necessidade de melhoria simultânea em ambos os equipamentos e não apenas de maneira isolada.

Em se tratando dos Equipamentos de Informática (Computadores, Internet, máquinas copiadoras, TV, Telefones e impressoras), os dados revelam que esses, diferentemente dos outros blocos, para produzir uma melhoria curricular positiva, irá depender minimamente da participação e do interesse do aluno pela escola. Ou seja, investimentos direcionados a esse rol de tecnologias se apresentam como uma alternativa "simples" e "rápida" para se obter melhores resultados, seja em avaliações internas ou em testes padronizados, fazendo desse equipamento um dos principais alvos no processo de elaboração e planejamento das políticas públicas educacionais. Esse entendimento ainda se alinha com Glewwe (2013), de acordo com a sua pesquisa, tal componente, quando empregado no contexto escolar, melhora o rendimento cognitivo dos estudantes e consequentemente o seu desempenho.

Assim, é possível perceber que não há por parte da própria literatura um consenso sobre a importância, e nem o impacto, de cada uma dessas variáveis no tocante ao aprendizado do aluno. O que há na verdade é uma compreensão, com base nos estudos feitos, de que a infraestrutura se constitui como uma ferramenta importante para o desenvolvimento escolar dos alunos, fazendo dela uma pauta recorrente na formulação de políticas públicas. Ainda de acordo com Glewwe (2013), isso se dá muito provavelmente em virtude da abordagem empírica escolhida nestas pesquisas, o que acaba afetando os seus resultados e no caso da infraestrutura, compreende-se que, em muitos pontos, os estudos empíricos não levam a conclusões definitivas sobre a sua importância (ou não).

Dessa maneira, mesmo que os resultados aqui apresentados sejam de relevância acadêmica, melhorias no modelo econométrico podem ser implementadas com o intuito de resolver as possíveis falhas existentes entre a variável resposta e as variáveis explicativas. 


\section{Referências}

ALBERNAZ, Ângela; FERREIRA, Francisco H. G.; FRANCO, Creso. Qualidade e equidade na educação fundamental brasileira. Texto para Discussão $n^{\circ} 455$. Rio de Janeiro: PUC-Rio, 2002.

ANDRADE, Dalton F. de; TAVARES, Heliton R.; VALLE, Raquel da C. Teoria de Resposta ao Item: conceitos e aplicações. São Paulo: Associação Brasileira de Estatística - ABE, 2000.

ANTUNES, Celso. Novas maneira de ensinar, novas formas de aprender. Porto Alegre: Artmed, 2002.

AZANHA, José Mario Pires. Democratização do ensino: vicissitudes da ideia no ensino paulista. Educ. e Pesq. São Paulo, v. 30, n. 2, p. 335-344, mai./ago. 2004.

BARBOSA, Maria Eugênia F; FERNANDES, Cristiano. A escola brasileira faz diferença? Uma investigação dos efeitos da escola na proficiência em matemática dos alunos da $4^{\text {a }}$ série. In: FRANCO, Creso (Org.). Avaliação, ciclos e promoção na educação. Porto Alegre: Artmed, 2001.p. 121-153.

BARBOSA, Maria Carmem Silveira; HORN, Maria da Graça Souza. Organização do espaço e do tempo na escola infantil. In: CRAIDY, Carmem (Org.). Educação infantil: pra que te quero? Porto Alegre: Artmed, 2001. p. 67-79

BEATON, Albert E; ALLEN, Nancy L. Interpreting scales through scale anchoring. Journal of Educational Statistics, v. 17, p. 191-204, 1992.

BID - Banco Interamericano de Desenvolvimento - Infraestructura Escolar y Aprendizajes en la Educación Básica Latinoamericana: Un análisis a partir del SERCE - 2011 Disponível em:http://www.iadb.org/pt/noticias/artigos/2011-10-18/infraestrutura-escolar-e-reducacionais-america-latina,9615.html.

BOBBIO, Norberto. A era dos direitos. Rio de Janeiro: Elsevier, 2004.

BONTORIM MAURIA BELTRAME ; MOURA, G. R. S. . Edificações escolares: infra-estrutura necessária ao processo de ensino e aprendizagem. Travessias (UNIOESTE. Online), v. 3, p. 1-15, 2009.

BRASIL. Padrões Mínimos de Qualidade do Ambiente Escolar, Fundo de Fortalecimento da Escola FUNDESCOLA / MEC.2006. 
Decreto no 5296, de 2 de dezembro de 2004. Disponível em: http://www.planalto.gov.br/CCIVIL-ato2004. Acesso em: 5 junho. 2017.

Constituição da República Federativa do Brasil, 1988. Disponível em: http:// www.planalto.gov.br. Acesso em: 5 junho. 2017.

BRADLEY, R. H et al. (1998). Home environment and school performance: a ten-year follow-up and examination of three models of environmental action. Child Development, 59, p. 852-867. In: A medida do capital cultural familiar no desempenho escolar $-18^{\circ}$ Congresso Brasileiro de Sociologia.

BUCHMANN, C.; HANNUM, E. Education and stratification in developing countries: a review of theories and research. Review of Sociology, v. 27, p. 77-102, 2001.

CARVALHO, José Sérgio Fonseca. “Democratização do ensino” revisitado. Educação e Pesquisa, São Paulo, v. 30, n. 2, p. 327-334, mai./ago. 2004.

CASTRO, Cláudio de Moura; FLETCHER, Philip. A escola que os brasileiros frequentaram em 1985. Rio de Janeiro: Ipea, Iplan,1986.

CAVALCANTI, L.S. Geografia e práticas de ensino. Goiânia: Alternativa, p.31-32, 2002.

CERQUEIRA, C. A.; SAWYER, D. R. O. T. Tipologia dos estabelecimentos escolares brasileiros. Revista brasileira de Estudos Populacionais, São Paulo, v. 24, n. 1, p. 5367, jan./jun. 2007.

COLEMAN, J. S.; CAMPBELL, E. Q. (1966). Equality of Educational Opportunity. Washington DC: US Government Printing Office. In: A medida do capital cultural familiar no desempenho escolar $-18^{\circ}$ Congresso Brasileiro de Sociologia.

CONNORS, L. J.; EPSTEIN, J.L. (1995).Parent and school partnerships. In: M. A. Bornstein (Ed.) Handbook of parenting. Vol.4, Applied and practical parenting. Mahwah, NJ: Lawrence Erlbaum, p.437-458. In: A medida do capital cultural familiar no desempenho escolar $-18^{\circ}$ Congresso Brasileiro de Sociologia.

DAVIS, Claudia. OLIVEIRA, Zilma. Psicologia na educação. São Paulo: Cortez, 1993.

DESSEN, M. A.; POLONIA, A. C. (2007). A família e a escola como contextos de desenvolvimento humano. Paideia - Cadernos de Psicologia e Educação, 17,36, p. 21 32. In: A medida do capital cultural familiar no desempenho escolar $-18^{\circ}$ Congresso Brasileiro de Sociologia. 
DEARING, E. et al. (2006). Family involvement in school and low-income children's literacy: Longitudinal Associations between and within families. Journal of Educational Psychology, vol.98(4), p.653-664. in: A medida do capital cultural familiar no desempenho escolar $-18^{\circ}$ Congresso Brasileiro de Sociologia.

DUARTE, Jesús; GARGIULO, Carlos; MORENO, Martín. School infrastructure and learning in Latin American elementary education: an analysis based on the Serce. Inter-AmericanDevelopmentBank, 2011.

DIDONET, Vital, 2002, texto programa Salto para o Futuro, Escola do sonho á realidade, Padrões mínimos de qualidade do ambiente escolar. in: http://cdnbi.tvescola.org. br/resources/VMSResources/contents/document/publicationsSeries/122307Aescolaqueremos.pdf. acesso em: 23 mar. 2018.

DING, W AND LEHRER, S. F. Do peers affect student achievement in china's secondary schools? The Review of Economics and Statistics, v. 89(2), p. 300-312, May, 2007. In: RAPOSO, Isabel Pessoa de Arruda. O papel da rede de amizades e da formação aleatória de turmas por faixa etária sobre o desempenho escolar. Recife: UFPE, 2015.

EDUCAÇÃO, Todos Pela, 2016. Taxa de conclusão do Ensino Médio aos 19 anos aumenta 15 pontos percentuais em dez anos - Reportagens TPE. in: https://www.todospelaeducacao.org.br/reportagens-tpe/36965/em-uma-decada-taxa-de- conclusao-do-ensino-fundamental-cresce-15-pontos-percentuais/. Acesso em: 23 abril 2018.

FLETCHER, Philip R. À procura do ensino eficaz. Relatório técnico. Departamento de Avaliação da Educação Básica. Brasília: MEC-Daeb, 1998.

FORNEIRO, Lina Iglesias. A Organização dos Espaços na Educação Infantil. In: ZABALZA, Miguel A. Qualidade em educação infantil. Tradução Beatriz Affonso Neves. Porto Alegre: Artmed, 1998.

FUNDAÇÃO JOAQUIM NABUCO. Coordenação de Estudos Econômicos e Populacionais. (2013). Acompanhamento longitudinal do desempenho escolar de alunos da rede pública de ensino fundamental do Recife.

Eficiência Educacional das Escolas Públicas do Ensino Fundamental do São Francisco Pernambucano: Uma Avaliação a partir da Técnica de Análise Envoltória de Dados, 2009.

GIL, Antonio Carlos. Como elaborar projetos de pesquisa. 4. ed. São Paulo: Atlas, 2002. 
GLEWWE, ET AL. (2013). "Education Policy in Developing Countries".TheUniversity of Chicago Press. Citado em: "O Impacto da Infraestrutura Escolar no Rendimento dos Alunos" (2014).

GROSSI, E. Como areia no alicerce: ciclos escolares. São Paulo: Paz e Terra, 2004.

HARRIS, J. R. Where is the child's environment? A group socialization theory of development.PsychologicalReview, v. 102(3), p. 458-489, 1995. In: O papel da rede de amizades e da formação aleatória de turmas por faixa etária sobre o desempenho escolar.

HATTIE, John. Visible learning. A synthesis of over 800 meta-analyses relating to achievement. London and New York: Routledge, Taylor \& Francis Group, 2009.

HORN, Maria daGraça de Souza.Sabores, cores, sons, aromas. A organização dos espaços na educação infantil. Porto Alegre: Artmed, 2004.

JESUS, Girlene Ribeiro de; Laros, Jacob Arie. Eficácia escolar: regressão multinível com dados de avaliação em larga escala. Avaliação Psicológica, v. 3, n. 2. Porto Alegre, nov. 2004, p. 21-31.

KLEIN, R. Utilização da Teoria de Resposta ao Item no Sistema Nacional de Avaliação da Educação Básica (Saeb). Ensaio, Rio de Janeiro, v. 40, n. 11, p. 283-296, 2003.

KRAMER, Sônia. Com a pré-escola nas mãos. São Paulo: Ática, 2000.

KRUEGER, James; LEWIS-BECK, Michael. (2008). "Is OLS Dead?" The Political Methodologist, vol 15, no 2: 2-4. In FIGUEIREDO FILHO, Dalson et al. O que fazer e o que não fazer com a regressão: pressupostos e aplicações do modelo linear de Mínimos Quadrados Ordinários (MQO). Revista Política Hoje, v. 20, n. 1, 2011.

LEE, V. L. Utilização de modelos lineares hierárquicos lineares para estudar contextos sociais: o caso dos efeitos da escola. In: BROOKE, Nigel; SOARES, José Francisco (Ed.). Pesquisa em eficácia escolar: origem e trajetórias. Belo Horizonte: Editora da UFMG, 2008. p. 273-296.

LEAL, Adílio Alves; FONSECA, Gildette Soares. (2008), “Território: Categoria geográfica das múltiplas perspectivas", trabalho apresentado no XV Encontro Nacional de Geógrafos, São Paulo.

MELO, Patrícia; CAMPOS, Luis Henrique Romani de; CAMBOIM, Michela; RAPOSO, Isabel. (2017). A medida do capital cultural familiar no desempenho escolar. $\mathbf{1 8}^{\circ}$ Congresso Brasileiro de Sociologia, 2017, Brasília. Que sociologias fazemos? Interfaces com os contextos locais, nacionais e globais. Brasília: Universidade de Brasília, 2017. 1. 23. 
MANSKI, C. F. Identification of endogenous social effects: the reflection problem. The Review of Economic Studies, v. 60(3), p. 531-542, Jul., 1993. In: : O papel da rede de amizades e da formação aleatória de turmas por faixa etária sobre o desempenho escolar.

NETO, Joaquim José Soares et al. Uma escala para medir a infraestrutura escolar. Estudos em Avaliação Educacional, v. 24, n. 54, p. 78-99, 2013.

OLIVEIRA, Marcos Ruben de; LAROS, Jacob Arie. Construtos mensurados no Censo Escolar 2002 - Ensino Fundamental. Revista Electrónica Iberoamericana sobre Calidad, Eficacia y Cambio en Educación, v. 5, n. 2e, 2007.

PATACCHINI, E, RAINONE, E AND ZENOU, Y. Dynamic aspects of teenage friendships and educational attainment,CEPR Discussion Paper 8223, 2011. In: O papel da rede de amizades e da formação aleatória de turmas por faixa etária sobre o desempenho escolar.

PINTO, C. C. X. Semiparametric estimation of peer effects.2008. Tese de Doutorado - University of California, Berkeley. In: O papel da rede de amizades e da formação aleatória de turmas por faixa etária sobre o desempenho escolar.

PNE. Observatório do - Estratégias do Plano Nacional da Educação - MEC/Inep/ Deed/Censo Escolar. Recife: 2015. Disponível em: http://www.observatoriodopne. org.br/metas-pne/7-aprendizado-adequado-fluxo-adequado/estrategias/7-18-infraestrutura . Acesso em: 8 de jun. 2017.

QEDU, Use dados. Transforme a educação - Matrículas e Infraestrutura, 2011. Disponível em: http://www.qedu.org.br/estado/117-pernambuco/censo-escolar? year $=2011$ \&localization $=0 \&$ dependence $=0 \&$ education_stage $=0 \&$ item $=-$ servicos. Acessado em 25 jul. 2017.

RECIFE. Prefeitura. A cidade do Recife. Disponível em: http://geo.dieese.org.br/recife/perfil_territorio.php?area=2 Acesso em: 20 jul.2017.

RODRIGUES, Margarida Maria Mariana. Instrumentos de avaliação educacional: uma visão pedagógica e psicométrica integradas, estudo das provas do SaebEst. Aval. Educ., São Paulo, v. 24, n. 54, p. 78-99, jan./abr. 201399 de Matemática 8a série - 1997 e 1999. Dissertação (Mestrado em Psicologia) - Instituto de Psicologia, Universidade de Brasília, Brasília. 2002.

SEPLAG, Pacto Pela Educação, 2011. Citado em:"Avaliação de Impacto da Política de Gestão por Resultados do Pacto Pela Educação do Governo do Estado de Pernambuco. 2015. 
Pacto Pela Educação, 2011. Disponível em: http://www.seplag.pe.gov.br/ web/pped/pacto-pela-educacao Acesso em 25 jul 2017.

SINTEPE - Sindicato dos Trabalhadores em Educação do Estado (Sintepe) - " $\boldsymbol{A}$ infraestrutura das escolas públicas estaduais de Pernambuco", 2014. Disponível em: https://www.sintepe.org.br/site/v1/index.php/saiunamidia/4268-sintepe-divulga-pesquisa-sobre-infraestrutura-escolar-no-estado> Acessado em 18/07/2017 às 17:43.

SOARES, J. F.; COLLARES, A. C. M. (2006). Recursos Familiares e o Desempenho Cognitivo dos Alunos do Ensino Básico Brasileiro. Revista de Ciências Sociais, Rio de Janeiro, Vol.49(3), p.615-650. In: A medida do capital cultural familiar no desempenho escolar $-18^{\circ}$ Congresso Brasileiro de Sociologia.

SOMMER, R. (1973). Espaço Pessoal. São Paulo: EDUSP, by: O ambiente da escola - o ambiente na escola: uma discussão sobre a relação escola-natureza em educação infantil. Gleice Azambuja Elali, Disponível em: http://www.scielo.br/pdf/epsic/ v8n2/19047.pdf em: 8 jun. 2017.

SOUZA, J. (2009). A ralé brasileira: quem é e como vive. Belo Horizonte: Ed. UFMG. In: A medida do capital cultural familiar no desempenho escolar - $18^{\circ}$ Congresso Brasileiro de Sociologia.

STEVEMSON, D. J.; BAKER, D. P. (1987).The Family-school relation and the child's school performance.Child Development, 58, p. 1348-1357. In: A medida do capital cultural familiar no desempenho escolar $-18^{\circ}$ Congresso Brasileiro de Sociologia.

ULINE, Cynthia; TSCHANNEN-MORAN, Megan. The walls speak: The interplay of quality facilities, school climate, and student achievement. Journal of educational administration, v. 46, n. 1, p. 55-73, 2008.

WOOLDRIDGE, Jefrey M. Introdução à econometria: uma abordagem moderna. São Paulo: Cengage Learning, 2008.

ZABALZA, Miguel,A. Qualidade em educação infantil. Porto Alegre: Artmed.1998. 